\title{
Acoustical properties of wood in string instruments soundboards and tuned idiophones: Biological and cultural diversity ${ }^{\text {a) }}$
}

\author{
Iris Brémaud ${ }^{\text {b) }}$ \\ Laboratoire de Mécanique et Génie Civil (LMGC), CNRS, Université Montpellier 2, Place Eugène Bataillon, \\ cc 048, 34095 Montpellier Cedex 5, France
}

(Received 15 December 2010; revised 24 March 2011; accepted 25 March 2011)

\begin{abstract}
The acoustical properties of wood for instruments have mostly been studied on a few archetypal woods in Western musical instruments. The objective of this paper is to extend knowledge on the diversity in wood properties and uses in instruments from different geo-cultural areas. A wide set of data has been collected on vibrational properties of 452 species, through experiments and literature survey. Property distributions within broad categories confirm the known characteristics of softwoods, but also evidence specificities of tropical hardwoods compared to temperate-zone species. A relational database has been created to link wood properties and uses in musical instruments of the world. Two case studies on acoustically important functions in different geo-cultural areas show contrasted trends: (i) species used for xylophone bars and slit-drums in different continents all share a very low internal friction, (ii) on the contrary, the only characteristic common to soundboards' woods is a lower than average density, whereas their acoustical properties differ widely between them and with the "Western" standard in wood choice. All these materials being nevertheless adapted to their context, cultural specificities in the structure, playing mode and "sonority" preferences should also be taken into account. (C) 2012 Acoustical Society of America. [DOI: 10.1121/1.3651233]
\end{abstract}

PACS number(s): 43.75.Kk, 43.75.Gh, 43.75.De, 43.35.Mr [TRM]

Pages: $807-818$

\section{INTRODUCTION}

Wood, as the constitutive material of many musical instruments, plays a major role in their design and building process, and contributes to their behavior and cultural identity. Wood material properties can impact, primarily, the acoustic response, but also mechanical resistance, physical stability, visual aesthetics, tactile properties, or a combination of these. The contribution of wood vibrational properties to the physical acoustics of a complete instrument depends on the part considered and family of instrument (e.g., Fletcher and Rossing, 1998; Wegst, 2006). They play a direct role in idiophone instruments, such as xylophones, in which wood constitutes the primary vibrating body. In string instruments, their importance is widely recognized for soundboards, which serve to transmit and radiate the vibration of a string, and act as a "filter" that colors the timbre. Relevant properties include density $(\rho)$ and dynamic Young's modulus $\left(E^{\prime}\right)$ and their ratio $\left(E^{\prime} / \rho\right)$, called specific modulus, which is proportional to the square of sound propagation speed and of resonance frequencies of a piece of given geometry. Given the significance of vibration damping in musical instruments, internal friction $(\tan \delta)$ is especially relevant, being an intrinsic material property, as opposed to other loss mechanisms such as by radiation (e.g., Fletcher and Rossing, 1998). The anisotropy of these properties plays

\footnotetext{
${ }^{\text {a) }}$ Preliminary portions of this work were presented at a meeting of COST Action IE0601, Wood Science for the Conservation of Cultural Heritage, in Braga, Portugal, November 2008.

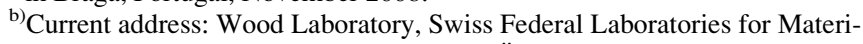
als Science and Technology (Empa), Überlandstrasse 129, CH-8600 Dübendorf, Switzerland. Electronic mail: iris_bremaud@hotmail.com
}

an important role in the vibration modes of plates and on the frequency response spectrum, related to "timbre" (Bucur, 2006; Yano, et al. 1994; Obataya et al., 2000).

However, wood being produced by living beings (trees from different species in their environment), and most highgrade musical instruments being also produced by living beings (makers of different musical instruments in their cultural context), diversity and variability are inherent to this topic. Apart from the Western classical musical instruments, nowadays spread worldwide, a huge diversity in instruments is found throughout different geo-cultural areas. Many of them are thought to share common origins, but to have evolved along different geo-historical pathways, linked with local flora and musical and craftsmanship cultures. With several tens of thousands of wood producing species, the potential range in material possibly used for instrument making is huge; however most species have a delimited geographical distribution. Thus, one might wonder if there is convergence, or on the contrary divergence, in the criteria for material choice between different areas?

As musical instruments combine acoustical and cultural functions, woods chosen for their building have been studied from two distinct viewpoints. Some ethnographic works include surveys and botanical identification of various species used in, usually extra-European, traditional instruments (e.g., Dechamps, 1972, 1973; Salazar Salvatierra, 1994). On the other hand, researches in musical acoustics and/or wood mechanics address wood vibrational properties (e.g., Ono and Norimoto, 1983; Yano et al., 1990, 1992; Holz, 1996a; Haines, 2000; Obataya et al., 2000; Bucur, 2006) and their influence in the instrument behavior (e.g., Schelleng, 1963; Hase, 1987; Barlow, 1997; Fletcher and Rossing, 1998; Wegst, 2006). But they are mostly based on a few archetypal 
woods in Western classical musical instruments, such as "resonance" spruce, or rosewood. Few connections, if any, exist between "diversity" and "acoustics" approaches. Only recently has emerged a very few works on the acoustic properties of some woods in Asian (Rujinirun et al., 2005; Yoshikawa, 2007) or African (Traoré et al., 2010) instruments.

The present work aims at bridging the gap between the diversity in wood species and traditional uses in musical instruments, and acoustical properties. It focuses on viscoelastic (i.e., including internal friction) vibrational properties, as data on this topic are up to now scattered and scarce. The central objective here is to determine whether the material choice for two acoustically important parts of instruments (chordophones soundboards and tuned idiophones vibrating bodies) could be considered as invariants in terms of acoustical properties. Or, on the contrary, if this choice would be different between geo-cultural areas, related to cultural aspects, or available wood species, or both.

\section{CHARACTERIZATION AND COMPILATION OF VIBRATIONAL PROPERTIES OF WOOD}

\section{A. Experimental characterization}

\section{Material}

Two main wood samplings were studied, covering the three broad categories of softwoods, temperate and tropical hardwoods. One sampling was provided by skilled instrument makers (eight French makers). It comprised mostly woods used for several string instruments, and a smaller set for xylophones, including both traditionally preferred and some potential alternative species. When necessary, the species identification was verified. Specimens mostly came from pieces actually used for building instruments, and when possible with the "quality" appreciations stated by the makers. Another sampling of many different species was collected from various sources, mainly from the well-identified wood stocks from CIRAD, in Montpellier, France. The total sampling under study contained a total of nearly 1400 test specimens prepared from 79 species (55 tropical and 12 temperate hardwoods and 12 softwoods). All the studied wood had been stored for several years in ambient conditions before testing.

\section{Method}

Specimens $\left(12 \times 2 \times 150 \mathrm{~mm}^{3}\right.$, radial $\times$ tangential $\times$ longitudinal) were first dried, in order to reach equilibrium in adsorption, for $48 \mathrm{~h}$ at $60^{\circ} \mathrm{C}$. This mild drying did not significantly affect later measurements. All measurements were performed after at least 3 weeks stabilization at $20 \pm 1{ }^{\circ} \mathrm{C}$ and $65 \pm 2 \%$ relative humidity $(\mathrm{RH})$, as vibrational properties are highly dependant upon moisture content and its variations (Obataya et al., 1998). Density $\left(\rho\right.$ in $\left.\mathrm{g} \mathrm{cm}^{-3}\right)$ and equilibrium moisture content (EMC in \%) were recorded.

Vibrational tests used non-contact forced-released vibrations of free-free bars, as shown in Fig. 1 (e.g., Obataya et al., 2000). Specimens were made to vibrate through a thin steel plate (weight $15-20 \mathrm{mg}$ ) glued on one end, facing an electric magnet. Their displacement at a belly of vibration was measured using a laser triangulation displacement sensor. Vibration emission and acquisition were computerdriven using a semi-automated interface that was specifically developed for this purpose (Brémaud, 2006). A first, broadband frequency scan detected the first resonance frequency $\left(f_{R}\right)$, on which a second, narrow-band scan allowed determination of the quality factor $Q$ (bandwidth at half-power). Next, the excitation (fixed at $f_{R}$ ) was stopped and the logarithmic decrement $(\lambda)$ of amplitudes was recorded. Damping coefficient (or internal friction) expressed as $\tan \delta$ was calculated both in frequency $\left(\tan \delta \approx Q^{-1}\right)$ and in time $(\tan \delta$ $\approx \lambda / \pi$ ) domains. Both methods gave identical results on average. The specific dynamic modulus of elasticity $\left(E^{\prime} / \rho\right.$ in $\mathrm{MPa} \mathrm{m} \mathrm{mg}^{-1}$ or in $\mathrm{m}^{2} \mathrm{~s}^{-2}$ ) was deduced from the first $f_{R}$ according to the Euler-Bernouilli equation. Given the high slenderness (length/height ratio of 75) of specimens, the influence of shear and rotary inertia could be ignored. Measurement frequencies were in the range of 200-700 Hz. Tests were performed in triplicate for each specimen and mean error on properties was $\leq 5 \%$.

\section{B. Collection of literature data}

Experimental results were completed by an extensive literature survey on wood vibrational properties. Data were compiled from 40 sources, with systematic links to original

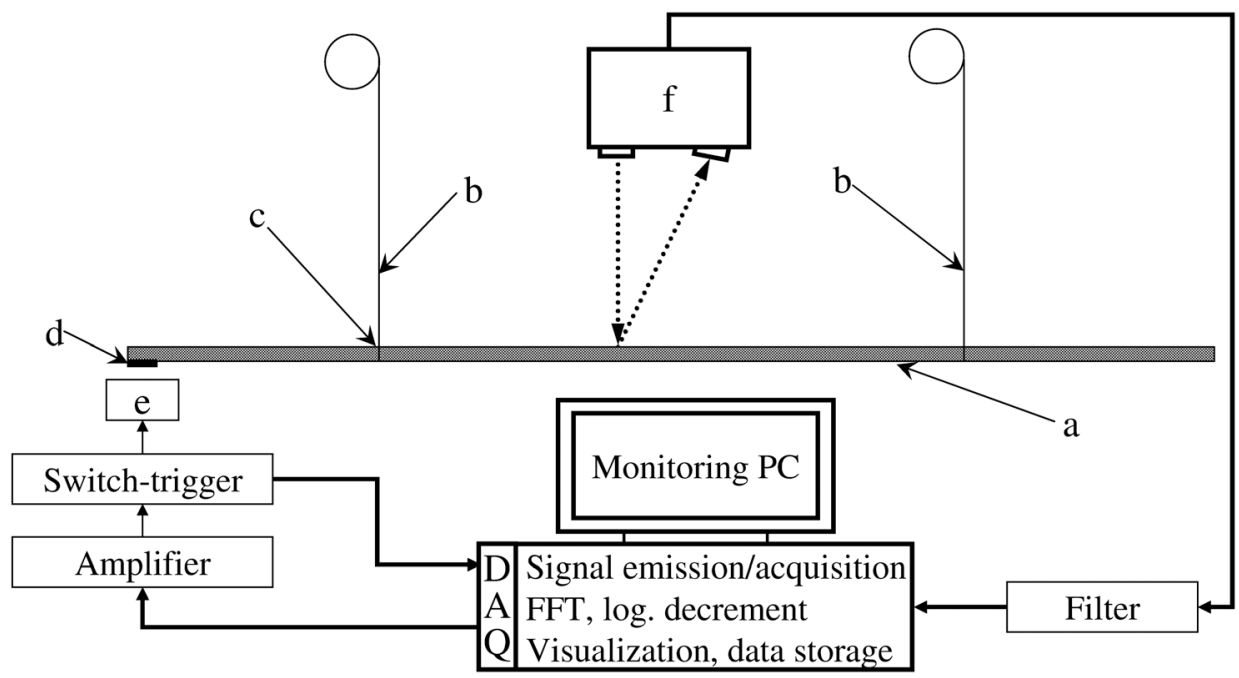

FIG. 1. Device used for characterizations of vibrational properties. (a) Wood specimen $(12 \times 2 \times 150) \mathrm{mm}^{3}$ $(R \times T \times L)$; (b) supporting silk threads; (c) location of vibration nodes for first bending mode; (d) thin steel piece glued onto one end of a specimen; (e) electro-magnet; (f) triangulation laser displacement sensor. 
references. Consistency of values was carefully checked, especially considering hygrothermal and frequency conditions. Most of the compiled data had been obtained on wood stabilized at $20-25{ }^{\circ} \mathrm{C}$ and ca. $65 \% \mathrm{RH}$, the standard "airdry" conditions for wood. The usual measurement range was of $200-1500 \mathrm{~Hz}$, in which vibrational properties are relatively independent of frequency (Ono and Kataoka, 1979).

The basic dataset includes $\rho, E^{\prime}, E^{\prime} / \rho$, and $\tan \delta$, along the grain. Some information on anisotropy of these properties was also collected for about a hundred species (Brémaud et al., 2011b). But up to now the full set of vibrational anisotropy (i.e., in three directions and three shear planes for both elastic moduli and internal friction) covers much fewer species. In the longitudinal direction, the "wood vibrational properties" database that has been compiled covers 452 woody species (corresponding to ca. 7000 tests), including 272 tropical hardwoods, 104 temperate hardwoods, 65 softwoods, 8 monocotyledons, and 3 lianas.

\section{CONSTRUCTION OF A RELATIONAL DATABASE: "WOOD SPECIES AND PROPERTIES IN MUSICAL INSTRUMENTS OF THE WORLD”}

The compilation of vibrational properties is included in a relational database on woods and instruments diversity created by the author (Brémaud et al., 2007). This tool gathers information on the uses of plant materials in musical instruments of the world, and allows relating such uses to the acoustical, mechanical and physical properties of materials. The other main data-tables include: "uses of woods in instruments" and "woody species taxonomy and information." All tables are dynamically connected (Fig. 2) which allows performing various queries. The whole database includes nearly 700 species, and some information on wood uses in about 160 instruments.

\section{A. Information on instrument making woods in different cultures}

Information about wood used in different geo-cultural areas has been collected from written sources of several disciplines: (ethno-) musicology, organology, ethno-botanics, forestry, wood science, and musical acoustics. Data from these scientific sources were complemented with those from technical treatises, wood suppliers, and direct interviews with makers. Up to now, data originate from ca. 50 sources in seven languages.
The central entity is the association between a given species and a given part of a musical instrument in a given context (region and/or epoch). When available, information is also included about the frequency of use, stated criteria for selecting this wood, and various observations at use. This module currently records 300 woody species cited in about 900 "species-instrument parts" associations (ca. 700 for structural parts) covering chordophones, idiophones, membranophones, and aerophones from 5 continents.

\section{B. Botanical aspects}

Botanical information is gathered in a single module for all species, either those used in instruments, or with data on vibrational properties, or both. The basic taxonomy (family, genus, species) is systematically verified. Two related modules list vernacular names in different languages, and invalid Latin names (synonyms or ancient nomenclatures) that can be encountered. Other types of information are also collected for part of the species, such as their geographic distribution, conservation status, or various descriptions of their wood.

This "botany" module is crucial, given that a unique and valid botanical name is the only possible key to ensure dynamic connections between data on properties and on uses.

\section{BIODIVERSITY AND DISTRIBUTION OF ACOUSTICAL - MECHANICAL PROPERTIES BETWEEN SPECIES}

Depending on the instrument part and geo-cultural context, the chosen wood can belong to different broad categories. Typically, the best-known species for soundboards are softwoods, and those for xylophone keys belong to the huge diversity of tropical hardwoods. In order to get a global view of the physical meaning of such categories, their distributions in density, Young's modulus and vibrational properties are compared in Fig. 3 over 441 wood species documented in our database.

Density distributions [Fig. 3(a)] obtained in this work confirm the known differences between softwoods (lighter materials with narrow distribution) and temperate or tropical hardwoods. The latter cover both the lowest and highest densities, and values of $\rho$ higher than $1.0 \mathrm{~g} \mathrm{~cm}^{-3}$ can barely be found outside of tropical hardwoods. Wood being a cellular material with nearly constant cell-wall density, $\rho$ mostly represents the porosity, i.e., the proportion of cell-wall material,

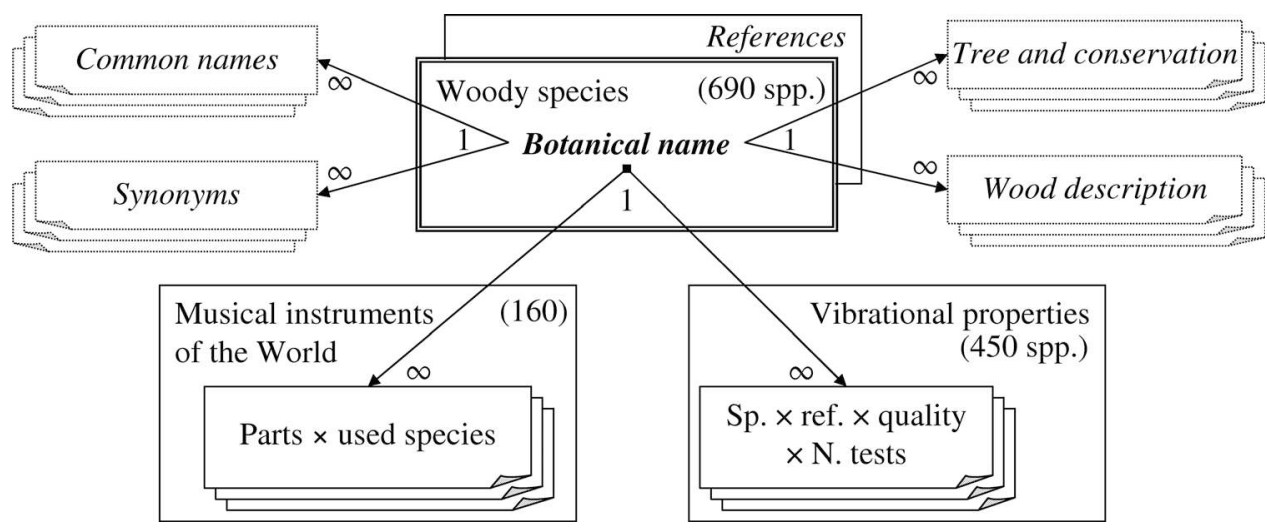

FIG. 2. Schematic architecture of the developed relational database "wood species and vibrational properties in musical instruments of the world." 

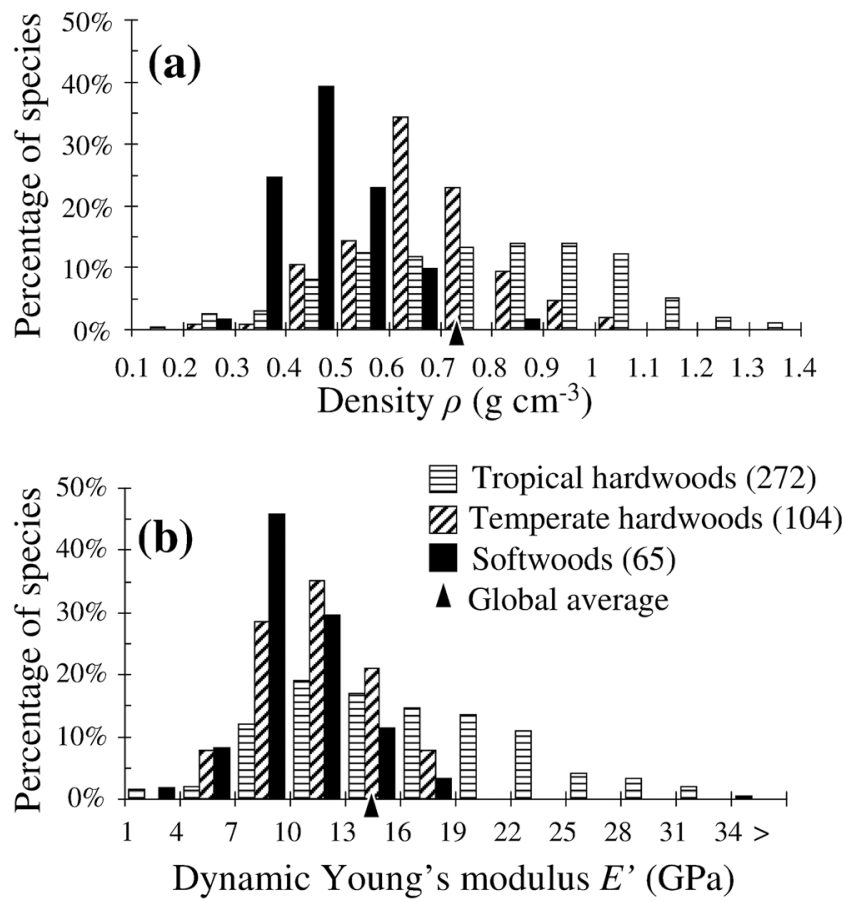
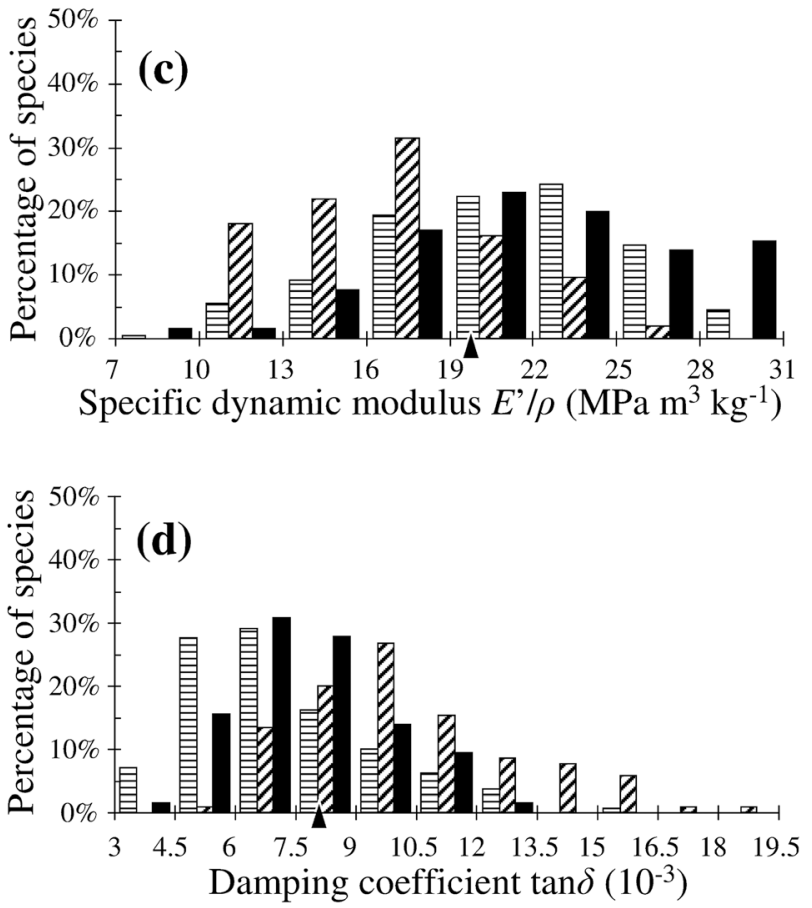

FIG. 3. Distribution patterns of (a) density $\rho$; (b) dynamic Young's modulus $E$ ' (c) and specific modulus $E$ ' $/ \rho$ and (d) internal friction (or damping coefficient) $\tan \delta$, on 441 species belonging to 3 broad categories: softwoods, and tropical or temperate hardwoods. Monocotyledon species are not represented as their number (8) is still too low in our database to be compared with other categories.

whereas $E^{\prime} / \rho$ and $\tan \delta$ are properties directly proportional to those of the cell-wall substance. Mean $E$ ' higher than $20 \mathrm{GPa}$ are observed only among tropical species [Fig. 3(b)], which can combine high values of both $E^{\prime} / \rho$ and $\rho$. The three broad categories differ significantly in their vibrational properties $\left[E^{\prime} / \rho\right.$ and $\tan \delta$, Figs. 3(c),3(d)]. Interestingly, the difference between temperate and tropical hardwoods is here obvious, as tropical ones show properties' distributions closer to softwoods. Softwoods are, however, distinguished by a "peak" towards highest values of $E^{\prime} / \rho$ [Fig. 3(c)], corresponding mostly to spruces (Picea genus). Temperate hardwoods, on the contrary, are mostly distributed towards lower $E^{\prime} / \rho$ values than the global average. Finally, the distributions in $\tan \delta$ [Fig. 3(d)] show that softwoods are nearly centered around the mean value for all woods, while temperate hardwoods mostly have higher $\tan \delta$ values. Although broadly distributed, tropical hardwoods include a majority of lower than average $\tan \delta$. The lowest (i.e., $\leq 0.006$ ) values of $\tan \delta$ are nearly exclusive to this category. The distributions in $\tan \delta$ are partly related to those in $E^{\prime} / \rho$. A rather strong negative correlation, common to softwoods and hardwoods, exists between $\tan \delta$ and $E^{\prime} / \rho$ of different specimens (Ono and Norimoto 1983, 1984). Data collected in the present work show that this "standard" trend is well conserved over average values of numerous species (Fig. 4). It explains, however, only $40 \%$ of the variability in $\tan \delta$ between species (TABLE I). This relation results from the effect on both properties of the orientation of wood elements, i.e., the angle of cellulose microfibrils within cell-walls (Obataya et al., 2000) and/or grain angle within a trunk or piece of wood (Brémaud et al., 2011b). The deviations of $\tan \delta$ from this standard trend are mainly related to chemical variations, and especially to some specific extractive compounds (Yano, 1994; Yano et al.,
1994,1995; Matsunaga et al., 1999; Brémaud et al., 2010, 2011a). Many tropical hardwoods have "abnormally low $\tan \delta$ " (down to $-60 \%$ ) as compared to the standard trend, probably due to their often high content of particular extractives. This, and their quite high proportion of high $E^{\prime} / \rho$ values (although similar to softwoods) explains the observed characteristic of very low $\tan \delta$ for tropical hardwoods.

These global distributions of properties thus indicate that tropical hardwoods used in some instruments parts may hardly be replaced by temperate substitutes when a very

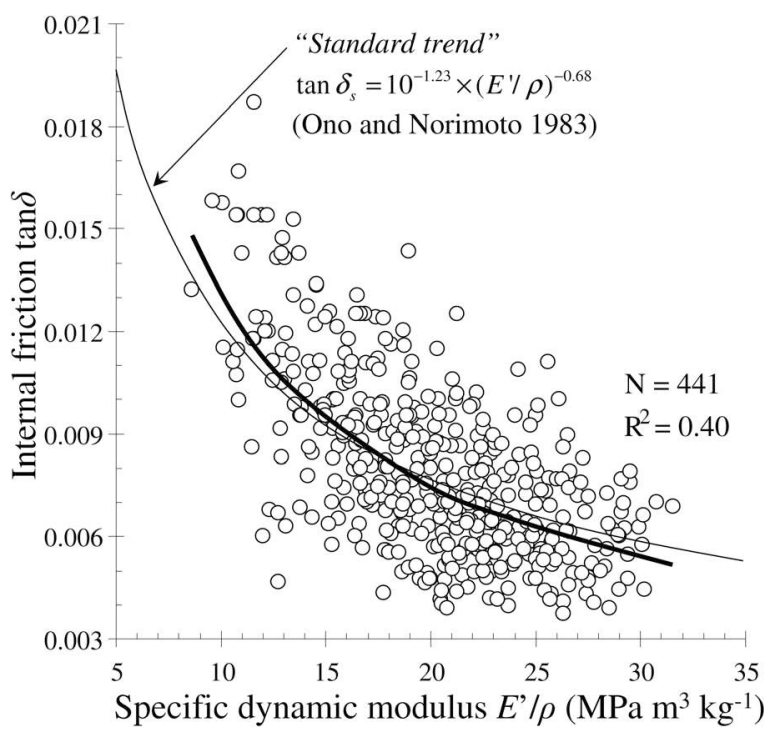

FIG. 4. Relation between the average damping coefficient (or internal friction, $\tan \delta)$ and the average specific dynamic modulus of elasticity $\left(E^{\prime} / \rho\right)$ for 441 species. 
TABLE I. Coefficients of determination $\left(R^{2}\right)$ for the linear correlations between basic properties (density $\rho$, Young's $E$ ' and specific $E$ ' $/ \rho$ modulus, internal friction $\tan \delta$ ) and with combined indexes (acoustic conversion efficiency ACE, characteristic impedance $z$ ), calculated between the average values of 441 species. (+) or (-): positive or negative significant relations.

\begin{tabular}{lcccc}
\hline \hline$N=441$ & $\rho$ & $E^{\prime}{ }_{L}$ & $E^{\prime}{ }_{L} / \rho$ & $\tan \delta$ \\
\hline$\rho$ & 1 & & & \\
$E^{\prime}{ }_{L}$ & $0.64(+)$ & 1 & & \\
$E^{\prime}{ }_{L} / \rho$ & 0.00 & $0.32(+)$ & 1 & 1 \\
$\tan \delta$ & 0.03 & $0.24(-)$ & $0.40(-)$ & $0.31(-)$ \\
$\mathrm{ACE}$ & $0.32(-)$ & 0.03 & $0.32(+)$ & $0.15(-)$ \\
$z$ & $0.87(+)$ & $0.93(+)$ & $0.12(+)$ & \\
\hline \hline
\end{tabular}

high density and/or Young's modulus, or a very low damping coefficient, are required.

However, the contribution of wood to the functioning of different instrument parts often involves several properties, which can be combined in "material performance indexes." Frequently used indexes include

$$
\begin{aligned}
& z=c \rho=\sqrt{E \rho}, \\
& R=\sqrt{\frac{E}{\rho^{3}}}, \\
& A C E=\frac{\sqrt{E / \rho^{3}}}{\tan \delta} .
\end{aligned}
$$

Detailed explanations of such indexes are given notably by Schelleng (1963), Barlow (1997), Wegst (2006), Yoshikawa (2007), and Obataya (2000). Very schematically, the "characteristic impedance" $(z)$ is related to the transmission of vibration from one medium to another, e.g., a string and a soundboard, or a soundboard and the air. The "radiation ratio" $(R)$ describes the average amplitude or loudness, whereas the "acoustic conversion efficiency" (ACE) represents the peak response (Barlow, 1997; Wegst, 2006). Ideally, if complete data were available on enough species, indexes accounting for anisotropy would also be desirable to get descriptors of "timbre", i.e., of frequency spectrum (Obataya et al., 2000; Aizawa et al., 1998; Barlow, 1997; Yano et al., 1994).

The distribution in ACE [Fig. 5(a)] shows that most temperate hardwoods are under the global average for this index, whereas tropical ones are rather centered on this value. Softwoods cover a broad range but mostly tend towards high values. A few percent of tropical hardwoods, however, also reach high ACE values. The distribution of $z$ [Fig. 5(b)] reveals that low characteristic impedance is mostly a characteristic of softwoods, although temperate hardwoods are here less different than in term of $\rho$ alone. Tropical hardwoods cover the widest range, including both lowest and highest values.

\section{WOODS USED FOR TUNED IDIOPHONES}

\section{A. On the quality requirements of woods for xylophones bars}

In idiophones, the primary vibrating part is the main structure of the instrument. The general term "xylophones"
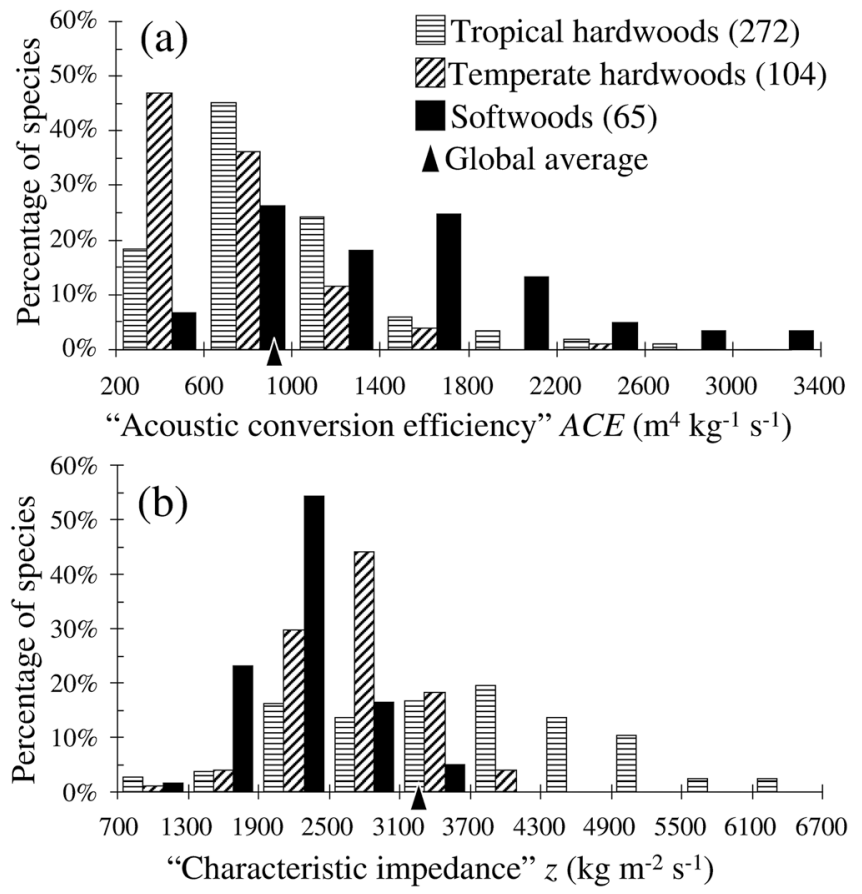

FIG. 5. Distribution patterns of some "material indexes of acoustical performance:" (a) "acoustic conversion efficiency" $\operatorname{ACE}\left(=\sqrt{E^{\prime} / \rho^{3}} / \tan \delta\right)$ and (b) "characteristic impedance" $z(=\rho c)$.

designates an arrangement of wooden bars with different pitches mounted on various types of supports. In Western instruments (concert marimbas and xylophones) the qualities required from wood were defined as high density, Young's modulus, impact hardness and resistance to wear and good moisture-related dimensional stability (Holz, 1996a). Being impulsively excited instruments, sound decay parameters are particularly relevant (Hase, 1987; Holz, 1996a; Brancheriau et al., 2006; Aramaki et al., 2007; Chaigne and Doutaut, 1997; Wegst, 2006). Xylophones for Western music are mainly built from a few species of true rosewoods (Dalbergia genus), although some artificial composites could also be employed. Trials with some temperate hardwoods with high internal friction gave poor results- "short and dull sounds" (Holz, 1996a). Across very different species unknown to this trade, sensory evaluation by a xylophone maker was very well correlated with decay time and internal friction $\tan \delta$ (Brancheriau et al., 2006). But not so with amplitude, eigenfrequency nor $E ' / \rho$. Normalization of the pitch by sound synthesis, in order to dissociate the effect of the geometry of the bar, emphasized damping of the first partial and spectral bandwidth as perceptual criteria (Aramaki et al., 2007). A good correspondence was found between the quality evaluation on trimmed parallelepiped bars, and on complete marimbas (Hase, 1987). Within the preferred species (Honduran rosewood), the best perceived material "quality" was also a very low $\tan \delta$ (Hase, 1987), even though $\tan \delta$ variability was then confined to its very lowest range for wood (0.0025-0.0055). Wegst (2006) suggested that woods for $\mathrm{xy}-$ lophone bars have rather high values of ACE (peak response) but not of $R$ (average loudness). Both their ACE and $R$ are lower than spruce for string soundboards, corresponding to lower damping by radiation, and their higher $z$ 
would cause less energy losses through the supports. Indeed, numerical modeling showed that decay times of xylophone bars was mostly determined by internal friction, but very little so by losses through the supports (Chaigne and Doutaut, 1997).

\section{B. Comparison of wood species and acoustical properties in tuned idiophones of different continents}

"Xylophones" are of recent introduction in the Western instrumentarium: they first appeared in European orchestral music at the end of the 19th century (although the general principle probably pre-existed, e.g., in the Basque Txalaparta). The historical pathways of xylophone-like instruments (Africa, S.E. Asia and Indonesia, Mesoamerica, and lately Europe) have been the subject of several hypotheses, although an African origin would now prevail. Slit-drums are another interesting type of wooden tuned idiophones. Their functioning is not strictly the same, as they are also Helmholtz resonators. Slit-drums have strong cultural importance in the Pacific regions and served for long-distance transmission of "spoken" messages in Africa (Carrington, 1976; Dechamps, 1972). The ranges in properties of several wood species traditionally selected in different continents for these two groups of idiophones are compared in Fig. 6.

The preferred wood for Western concert xylophones is Honduran rosewood (Dalbergia stevensonii). Its damping coefficient is among the very lowest of all woods represented in our database. Rio Rosewood ( $D$. nigra) has been used but its sound was considered "less bright" than Honduran, which is consistent with their respective $\tan \delta$ values. Interestingly, in Central-America (which hosts several Dalbergia species), the preferred woods for traditional marimbas are mainly from another genus: Platymiscium spp. (Kaptain, 1991; Salazar Salvatierra, 1994). According to available data, woods from this genus appear to have also a very low damping, yet sometimes lower density. Alternatively, Myroxylon balsamum is stated as "the most durable and resistant wood" but is not as much esteemed (Salazar Salvatierra, 1994). Its much higher $\tan \delta$ suggests that traditional choice strongly relied on acoustical criteria.

Xylophones and slit-drums are particularly important and diversified in Africa. Many species could be encountered in either xylophones designed for temporary use, or slit drums with strong aesthetical meaning, involving the ability of wood to be intricately carved (Déchamps, 1972, 1973). On the contrary, the more prominent the purely "acoustic" function of instruments was, the higher the proportion of use of Pterocarpus spp. (often P. soyauxii, African padauk, in Central Africa). This choice is nearly exclusive in most elaborate xylophones and in slit-drums that were used for message transmission-up to more than $10 \mathrm{~km}$ distances (Carrington, 1976; Dechamps, 1972, 1973). Padauk is not as dense as American xylophone woods, but its $\tan \delta$ is very low. This species has also been adopted in Western instruments (Richter, 1988). From Mali to Burkina Faso, another species of this genus (Pterocarpus erinaceus, often called Vène) is the preferred material for xylophones. Its properties partially overlap those of $P$. soyauxii, but tend towards higher density and internal friction. Its vibrational properties depend both on the geographic origin and on the location within the trunk, which coincide with traditional criteria of makers (Traoré et al., 2010).

Artocarpus spp. are used from S.E. Asia to Melanesia, either for xylophone-like instruments in S.E. Asia, which also use local species of Dalbergia (Rujinirun et al., 2005) or for slit-drums. For the monumental slit-drums of Vanuatu, Pterocarpus indicus is apparently considered as giving a "brighter" sound than Artocarpus species, ${ }^{1}$ which would be consistent with its lower $\tan \delta$. In Indonesia, both types of
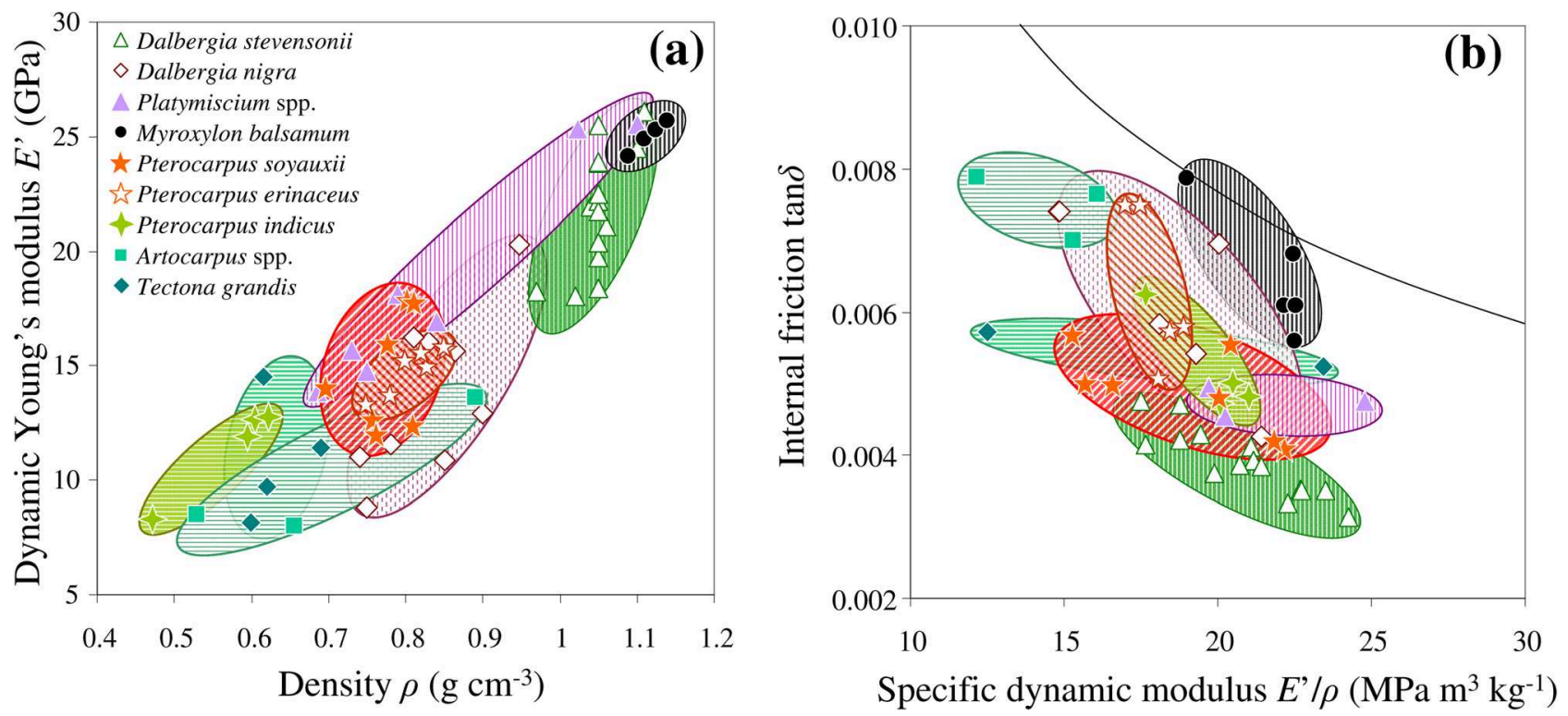

FIG. 6. (Color online) Ranges in density, dynamic Young's modulus (a) and vibrational properties (b) for some woods chosen for vibrating bodies of xylophones and slit-drums through different continents. Each mark is the average of a stock. Ellipses: known ranges in properties of the different species; vertical hatching: woods originating from Latin-America; horizontal: woods native to S.E. Asia and Oceania; diagonal: woods native to Africa. Curve in (b): standard relationship between $\tan \delta$ and $E^{\prime} / \rho$ (Ono and Norimoto 1983). 
instruments may use teak (Tectona grandis), which compares with both previous woods in its $\rho$ and $E^{\prime}$, but which low $\tan \delta$ is closer to $P$. indicus.

The average density (followed by $E^{\prime}$ ) shows a decreasing trend [Fig. 6(a)] between idiophone woods native to Latin America $\left(0.75-1.15 \mathrm{~g} \mathrm{~cm}^{-3}\right)$, Africa $\left(0.7-0.9 \mathrm{~g} \mathrm{~cm}^{-3}\right)$ and S.E. Asia-Oceania $\left(0.45-0.9 \mathrm{~g} \mathrm{~cm}^{-3}\right)$. This is consistent with the trends in distribution of density between continents obtained on 3000 species of hardwoods (Détienne and Chanson, 1996). On the other hand, vibrational properties of used species do not depend on areas [Fig. 6(b)]. Their specific modulus is centered on the mean value for wood $(20 \mathrm{MPa}$ $\mathrm{m}^{3} \mathrm{~kg}^{-1}$ ), but all these chosen woods have lower internal friction than the global average $(8 \%$ ). The differences in density are reflected in characteristic impedance (Fig. 7), but not in ACE ("peak response"). The lowest values of $z$ here belong to woods used in slit-drum-where impedance mismatch with supports is not relevant, but easy transmission of vibrations into the air is. The only wood with both very high $z$ and very low ACE is $M$. balsamum, stated as "not very good acoustically." Within the variability of Dalbergia stevensonii, or of D. nigra, ACE and $z$ are slightly correlated. This could correspond to the suggestion (Wegst, 2006) that high values of both factors are beneficial for xylophone bars. However, such a trend is not observed within nor between the other species (Fig. 7). Globally all these idiophones woods share quite intricate ranges of ACE.

This synthesis on some important woods in tuned idiophones indicates that (i) relatively high density is frequent, but far from being systematic; (ii) specific Young's modulus is not a key factor: changes in geometry can efficiently deal with actual frequencies and overtones during the tuning process; (iii) these woods selected for "xylophones" and/or slit drums are all characterized by low damping coefficients, irrespective of their $E^{\prime} / \rho$, and whatever the region of the

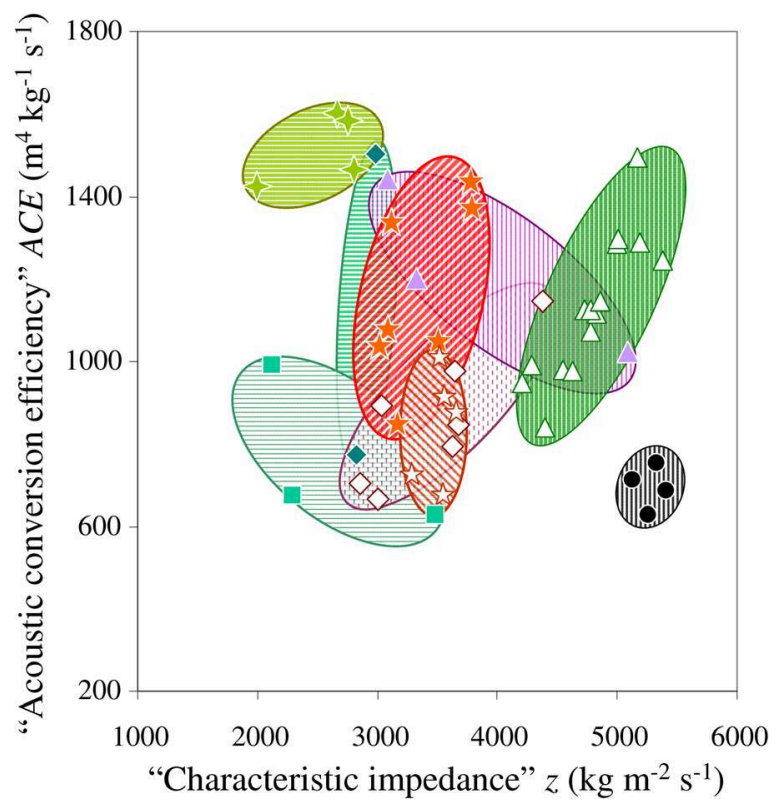

FIG. 7. (Color online) Ranges in "material indexes of performance" ACE and $z$ for some woods chosen for xylophones and slit-drums through different continents. Legend: see Fig. 6. world and local or imported flora. This finding supports and extends previous results which considered only Western musical instruments (Hase, 1987; Holz, 1996a; Wegst, 2006; Brancheriau et al., 2006; Aramaki et al., 2007). It also suggests that, in such idiophones, the acoustical role of the material predominates and leads to rather comparable choices in different continents and cultures.

Another interesting fact is that, apart from the Artocarpus spp. (Moraceae) and Tectona grandis (Verbenaceae), most of the species presented here belong to the same family (Leguminosae-Papilionoideae) and even to the same tribe (Dalbergioideae). These taxa are characterized, within wood biodiversity, by abnormally low internal friction (Brémaud et al., 2009). For some Dalbergia (Yano et al., 1994,1995) and Pterocarpus species (Brémaud et al., 2010, 2011a; Traoré et al., 2010), this was found to be due to their specific extractives. It suggests some connection between chemotaxonomy, and the empirical selection of these materials for acoustical functions throughout different continents.

\section{WOODS FOR SOUNDBOARDS OF STRING INSTRUMENTS}

In chordophones, as their name implies, the primary vibrating body is a tight string, set into vibration by plucking, striking or bowing. A resonator is needed to amplify and radiate the sound. In the most elaborate instruments, the string vibration is transmitted through a bridge to a soundboard. The material of the soundboard "should" allow for adequate transmission of energy from the string, limit losses, and be able to radiate efficiently (e.g., Fletcher and Rossing, 1998; Barlow, 1997; Wegst, 2006; Yoshikawa, 2007). It also serves as a filter, which colors the frequency spectrum and thus participate to timbre (e.g., Yano et al., 1994; Obataya et al., 2000; Haines, 2000). Due to the importance of string instruments in Western classical music, much research has been conducted on the acoustical properties of their soundboard wood, chiefly European spruce (Picea abies).

\section{A. On « resonance » spruce, the archetypal wood for soundboards of Western classical stringed instruments}

Spruce selected as high-grade has a quite low density $\left(\rho \approx 0.45 \mathrm{~g} \mathrm{~cm}^{-3}\right.$ ) and a very high specific modulus of elasticity (around 26-36 MPa m $\mathrm{kg}^{-1}$, leading to sound velocities up to $6000 \mathrm{~m} \mathrm{~s}^{-1}$ ) (e.g., Haines, 2000; Bucur, 2006; Yano et al., 1990; 1992). In spruce, internal friction $\tan \delta$ is very strongly negatively correlated to $E^{\prime} / \rho$, i.e., there is little extractive-related variability. So that high-grade samples are within the higher range of $E^{\prime} / \rho$ and the lower range of $\tan \delta$ for this species, due to a small angle of microfibrils in cell-walls (Ono and Norimoto, 1983; Yano et al., 1994; Obataya et al., 2000). This, and a structure with a majority of axial cells (tracheids), also determine a high axial-to-shear and axial-to transverse anisotropy (Obataya et al., 2000; Bucur, 2006).

Considering "acoustical performance," a very high $E$ ' $/ \rho$ combined with a low $\rho$ leads to high radiation ratio [Eq. (2)], and, together with quite low $\tan \delta$, high acoustic conversion efficiency [Eq. (3)]. From the standpoint of the coincidence 
frequency of plates, a high $E^{\prime} / \rho$ should ensure sufficient radiation at lower frequencies (Holz, 1996b). Being quite light, spruce has moderate characteristic impedance [Eq. (1)], which should benefit to sound transmission into the air (Wegst, 2006). Its high anisotropy strongly influences vibration modes of a soundboard, and thus frequency response (Barlow, 1997). As the apparent frequency dependence of $\tan \delta$ in bending results partly from the influence of shear (Ono and Kataoka, 1979), the high axial-to-shear anisotropy of spruce contributes to higher losses at high frequencies (Yano et al., 1994; Obataya et al., 2000).

However, properties of woods classified as "good," "medium," and "poor" for violin overlap, although "good" is closer to above trends and less variable (Yano et al., 1992). Quality grading (between many "resonance" and few "general" supplies) by several violin makers appeared hardly correlated to acoustical properties, but rather to physical and visual criteria (Buksnowitz et al., 2007). Indeed, density and parameters related to growth rings or color belong to transmitted knowledge as found in treatises. But they reflect only indirectly variations at the mechanically relevant, lower structural scales in wood (Kubojima et al., 1997; Hori et al., 2002). Additionally, violin structure, although constrained by historical models, allows for significant adjustments with its sculpted vault. The maker's know-how allows dealing with a non-optimal material by adjusting the construction. Luthiers generally reckon that they can build a good violin from a "medium" wood-but not from a "very poor" one. Empirical grading of piano top-plates followed similar trends and more related to acoustic properties, although pieces can be rejected for only visual defects (Ono and Norimoto, 1983; Norimoto et al., 1984). The geometry of guitar blanks allows testing "by hand" damping and longitudinal/radial stiffness. Classification is just slightly better defined by basic acoustic properties than for violins (Yano et al., 1990), but multi-variable psychosensorial analyses can reveal quite fine quality grading (Douau, 1986). Altogether, these different studies suggest that (i) wood selection and qualification by string instrument makers is by essence multi-criteria; (ii) the relative importance of mechanical/acoustical properties depends on the degree of freedom in the geometry of the instrument and/or of blank plates; (iii) properties of different instrumentmaking grades can overlap, but form a distinct group within the Picea abies variability, with much higher than average $E^{\prime} / \rho$ and anisotropy, and low $\tan \delta$.

\section{B. Comparison of other soundboard woods chosen in instruments from different geo-cultural areas}

Due to its acoustical performances and its cultural status of "historical resonance wood," European spruce is often considered as the "reference" to which all other woods for top plates should be compared or even matched.

Besides, other species of the Picea genus have been used in past decades in piano, guitar, and even violin-family. Table II compares axial vibrational properties of nine Picea species, either used in instruments or not, from different regions. Although the number and pre-selection of specimens is very different between species, most of them have properties with ranges very similar to Picea abies.

TABLE II. Average values \pm standard deviation of density, specific modulus of elasticity and internal friction of several species of spruce (Picea genus) from different origins, compared with other species of the Pinaceae family and other softwoods.

\begin{tabular}{|c|c|c|c|c|c|c|}
\hline Species & Distributional range $^{\mathrm{a}}$ & $\begin{array}{c}N \\
\text { Sources }\end{array}$ & $\begin{array}{c}N \\
\text { specimens }\end{array}$ & $\begin{array}{c}\rho \\
\left(\mathrm{g} \mathrm{cm}^{-3}\right)\end{array}$ & $\begin{array}{c}E_{L}^{\prime} / \rho \\
\left(\mathrm{MPa} \mathrm{m}^{3} \mathrm{~kg}^{-1}\right)\end{array}$ & $\begin{array}{l}\tan \delta_{L} \\
\left(10^{-3}\right)\end{array}$ \\
\hline Picea abies (L.) Karst. & Europe (North, Central and Eastern) & $9^{\mathrm{b}}$ & $1065^{\mathrm{e}}$ & $0.45 \pm 0.04$ & $28.4 \pm 3.9$ & $7.1 \pm 1.2$ \\
\hline Picea engelmannii Parry ex Engel. & North America (West Canada and USA, North Mexico) & $2^{\mathrm{b}}$ & $2^{\mathrm{f}}$ & $0.4 \pm 0.09$ & $28.5 \pm 0.7$ & $6.3 \pm 0.0$ \\
\hline Picea glauca (Moench) Voss & Northern America (Canada and North USA) & $1^{\mathrm{c}}$ & $3^{\mathrm{e}}$ & $0.46 \pm 0.03$ & $30.8 \pm 3.2$ & $7.0 \pm 0.3$ \\
\hline Picea rubens Sarg. & Northeastern America (Canada and USA) & $1^{\mathrm{c}}$ & $14^{\mathrm{e}}$ & $0.48 \pm 0.03$ & $27.1 \pm 7.8$ & $7.6 \pm 1.0$ \\
\hline Picea sitchensis (Bong.) Carr. & Northwestern America (Canada and USA) & $10^{\mathrm{b}}$ & $718^{\mathrm{e}}$ & $0.45 \pm 0.05$ & $28.7 \pm 4.6$ & $7.7 \pm 1.5$ \\
\hline $\begin{array}{l}\text { Picea brachytyla var. } \\
\text { complanata (Mast.) } \\
\text { Cheng ex Rehd. }\end{array}$ & South China to North Myanmar and India & $1^{\mathrm{d}}$ & $3^{g}$ & & $23.9 \pm 2.5$ & $8.0 \pm 0.3$ \\
\hline Picea glehnii (F. Schmidt) Mast. & North-Eastern Asia (Sakhalin, Kuriles and North Japan) & $3^{b}$ & $228^{\mathrm{e}}$ & $0.44 \pm 0.03$ & $29.0 \pm 2.9$ & $6.0 \pm 0.6$ \\
\hline Picea jezoensis (Sieb. et Zucc.) Carr. & $\begin{array}{l}\text { North-Eastern Asia (North of Japan, } \\
\text { China and Korea and Far-Eastern Russia) }\end{array}$ & $6^{\mathrm{b}}$ & $166^{\mathrm{f}}$ & $0.41 \pm 0.02$ & $29.9 \pm 3.0$ & $6.3 \pm 0.9$ \\
\hline Picea likiangensis (Franch.) Pritzel & South-West China to Bhutan & $1^{\mathrm{d}}$ & $6^{\mathrm{g}}$ & & $27.2 \pm 4.6$ & $8.2 \pm 0.7$ \\
\hline $\begin{array}{l}\text { Other woods of Pinaceae } \\
\text { ( } 26 \text { species from } 5 \text { genus })\end{array}$ & $\begin{array}{c}\text { Northern hemisphere (+ Mexico, Mediterranean } \\
\text { and S.E. Asia) }\end{array}$ & 7 & $104^{\mathrm{f}}$ & $0.48 \pm 0.08$ & $22.1 \pm 4.9$ & $7.9 \pm 2.0$ \\
\hline $\begin{array}{l}\text { Other softwoods } \\
\text { ( } 27 \text { species from } 15 \text { genus } \\
\text { in } 4 \text { families, Pinophyta) }\end{array}$ & Cosmopolitan (with different ranges and frequencies) & 13 & $333^{\mathrm{f}}$ & $0.44 \pm 0.11$ & $19.1 \pm 5.4$ & $7.8 \pm 2.4$ \\
\hline
\end{tabular}

${ }^{\mathrm{a}}$ Earle (2010).

${ }^{\text {b}}$ Data compiled from Aizawa (1998), Bucur (2006), Fukada (1950), Haines (2000), Hori et al. (2002), Norimoto et al. (1984), Yano et al. (1990; 1992), and from the author's work.

${ }^{c}$ Haines (2000).

${ }^{\mathrm{d}}$ Hori et al. (2002).

${ }^{\mathrm{e}}$ Specimens selected for instrument making.

${ }^{\mathrm{f}}$ Specimens partially selected for instrument making.

${ }^{\mathrm{g}}$ Specimens not specifically selected for instrument making. 

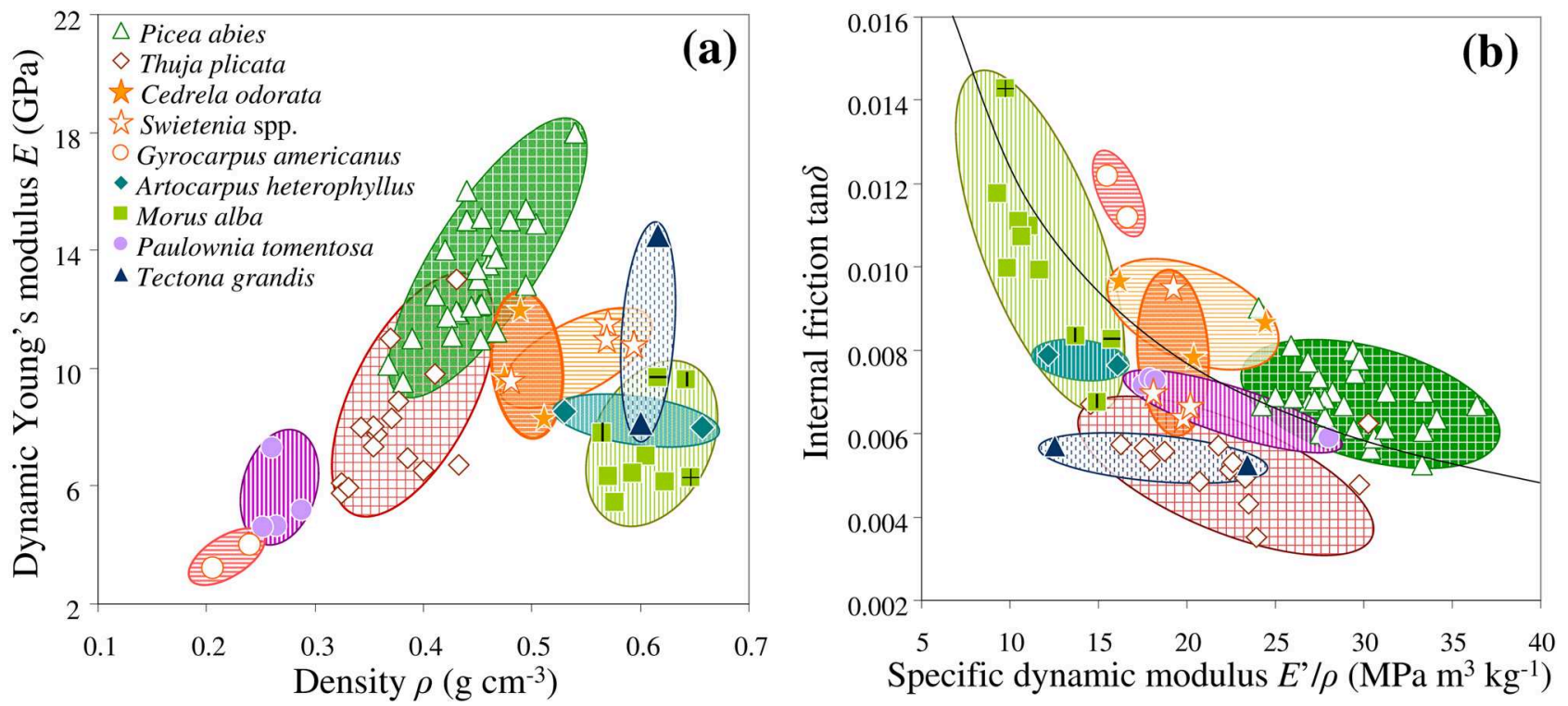

FIG. 8. (Color online) Ranges in density, dynamic Young's modulus (a) and vibrational properties (b) for some woods chosen for string instruments' top plates in different geo-cultural areas. Each mark is the average of a stock. Ellipses: known ranges of the different species; cross hatchings: typical woods in Western musical instruments; vertical: woods used in traditional instruments from Middle-East to Far-East Asia; horizontal: woods used in "folk" instruments of Latin-America. Curve in (b): see Fig. 6.

The main other wood for guitars' top plates, western red cedar (Thuja plicata, Cupressaceae), already deviates from the "spruce reference." Red cedar has quite lower density, specific modulus and characteristic impedance, much lower $\tan \delta$ and often higher "acoustical conversion efficiency" (Figs. 8 and 9) both in axial and radial directions (Yano et $a l ., 1990 ; 1992)$. Whereas the reduced $E ' / \rho$ can be easily dealt with by adjusting the thickness, the much lower $\tan \delta$ of red cedar might be desirable for plucked strings where vibration is not continuously excited. However, the choice of this species or of spruce is dictated by subjective preferences mainly based on timbre and responsiveness (Douau, 1986) which suggests that, even within a given instrument and musical culture, material selection is already linked to some musical/cultural specificities.

All the above researches only concern woods used in western classical musical instruments. But the possibility of generalizing conclusions to instruments from other cultures has seldom been questioned. In the previous analysis about xylophones' woods, some inter-continental constants in wood choice could be found. But the influence of the material was predominant, and the introduction in Europe is quite recent. In the case of string instruments, the materialstructure combination is most often quite complex, and historical-geographical pathways are much more ancient and intricate. An hypothesis is that this could have led to much deeper cultural differentiation. Indeed, many wood species are cited as being used for soundboards throughout the world. The database built by the author lists 82 occurrences with species belonging to 21 families-although the survey is far from being exhaustive, and some documented uses are probably anecdotal. However, data on vibrational properties are available for only a fraction of these species.

Table III lists some species frequently used in soundboards of Asian and Latin American ${ }^{2}$ string instruments, and for which data on vibrational properties are known (Fig. 8).
Quite striking differences appear between woods from different geo-cultural areas. Their only shared characteristic is lower density than the global average (i.e., $\rho \leq 0.7 \mathrm{~g} \mathrm{~cm}^{-3}$ ), also reflected in a lower than average characteristic impedance (Fig. 9). But their vibrational properties $E^{\prime} / \rho, \tan \delta$ and ACE cover most of the ranges known for wood. An important observation is that, while the notion of "soundboard wood" is often associated to softwoods, several hardwood species are chosen in Asia and in Latin America, although local resources in softwood can exist. The Picea genus is restricted to Northern regions, but several species, with properties similar to European spruce, are native to Japan and China or can be found in Mexico (Table II). Other genera of

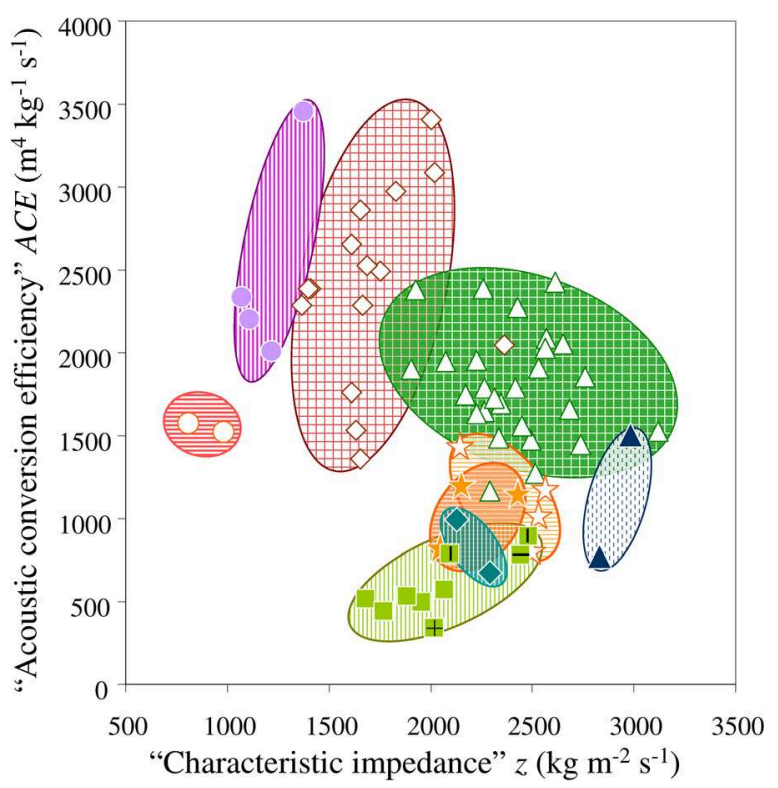

FIG. 9. (Color online) Ranges in "material indexes of performance" ACE and $z$ for some woods of string instruments' top plates in different geocultural areas. Legend: see Fig. 8. 
TABLE III. Some wood species used for soundboards of string instruments from different geo-cultural ensembles (Western classical music, Middle-East to Far-East Asia and Latin America) and for which data on vibrational properties are available.

\begin{tabular}{|c|c|c|c|c|}
\hline Species & Common names & Category & Instruments & Geo-cultural ensemble \\
\hline Picea abies (L.) Karst. & Spruce & Softwood & Violin family, Piano, Guitar, Lutes & «Western» \\
\hline Thuja plicata D. Don & Western Red Cedar & Softwood & Guitars & «Western» \\
\hline \multirow[t]{2}{*}{ Paulownia tomentosa (Thunb.) Steud. } & Paulownia & Hardwood & Pipa (short-necked lute) & China \\
\hline & & & Koto (harp-zither) & Japan \\
\hline \multirow[t]{2}{*}{ Morus alba $\mathrm{L}$. } & Mulberry & Hardwood & Biwa (short-necked lute) & Japan \\
\hline & & & Setar (long-necked lute) & Iran \\
\hline Artocarpus spp. & Jacqfruit tree & Hardwood & Vina, Tambura (long-necked lutes) & India \\
\hline Tectona grandis L. f. & Teak & Hardwood & Sitar, Tambura (long-necked lutes) & India \\
\hline Cedrela spp. & Cedro & Hardwood & Various folk instruments (plucked and bowed) & Latin America \\
\hline Swietenia spp. & Mahogany & Hardwood & Various folk instruments (plucked and bowed) & Latin America \\
\hline Gyrocarpus americanus Jacq. & Tacote & Hardwood & Harp, Guitarron, Vihuela (plucked strings) & Mexico \\
\hline
\end{tabular}

Pinaceae and other softwood families can be found on a wider range and, although they have lower vibrational properties in average, some could sometimes reach equivalent values.

In Central America, both local softwoods and hardwoods are used in traditional stringed instruments. These softwoods are not presented here, as data on their vibrational properties are lacking. But hardwoods such as Cedrela or Swietenia species (Meliaceae), which are also cited in South American countries where few softwoods grow, have properties close to the average of softwoods and at the lower margin of spruce (i.e., from similar to slightly higher $\rho$ and $\tan \delta$, lower $E$ ' $\rho$ and $A C E$, Figs. 8 and 9). A similarity in material properties may be consistent for instruments historically derived from European ones (as it seems that nearly no stringed instruments are known from pre-Hispanic times).

On the contrary, some woods used in Asia (from Middle-East to Far-East) are clearly different from the "Western" wood choice. The Paulownia used for Chinese lute Pipa and Japanese zither Koto has a very low density $\left(\approx 0.3 \mathrm{~g} \mathrm{~cm}^{-3}\right)$ and characteristic impedance, vibrational properties $E^{\prime} / \rho$ and $\tan \delta$ between spruce and red cedar, and ACE as high as or higher than spruce. On the other hand, the mulberry (Morus alba) used for Persian lute Setar and Japanese lute Biwa, and the jackfruit tree (Artocarpus spp.) and teak (Tectona grandis) used for Indian Sitar, Vina or Tambura have clearly higher $\rho$, lower $E$ ' $/ \rho$ and lower ACE (Figs. 8 and 9). Especially surprising is that the "superior" quality of mulberry selected for Biwa (Yoshikawa 2007) has the highest $\tan \delta$ of all wood lots represented in Fig. 8(b). Yoshikawa (2007) described mulberry as closer in properties to a back-plate than top-plate wood and discussed its choice for the Biwa. One explanation for using a material with very high internal friction and very low ACE was related to the "Sawari" mechanism in Biwa, a reverberating effect due to the "buzzing" vibration of strings on bridge or frets (Yoshikawa, 2007). However, Artocarpus and Tectona woods used for Indian instruments with a similar effect ("Jawari"), appear to have comparatively much lower $\tan \delta$ and quite higher ACE. The mulberry (Pourtahmasi and Se Golpayegani, 2008) selected by Iranian makers of instruments without such "buzzing" mechanism also has lower $\tan \delta$ and slightly higher ACE than the superior one for Japanese Biwa. There was more difference between two "qualities" of mulberry from Japan, than between different growth origins. Similarly, no significant differences were found between vibrational properties of Paulownia tomentosa from Japan or China (Minato et al., 2005). Wood choice in Biwa and Pipa is interesting as geometries are more comparable than with other considered instruments. Yoshikawa (2007) suggested that the more "efficient" but fragile Paulownia would be better suited for Pipa, without "buzzing" effect, played with fingertips instead of being stroked with a wide wooden plectrum, and with different sound expectations. Playing techniques could also justify the choice of Paulownia for the thick soundboard or the Koto zither, in relation to the structure of the instrument (Yoshikawa, 2007).

Altogether, all soundboards species considered here are not so much differentiated according to "characteristic impedance" (Fig. 9), except for Paulownia and Gyrocarpus, used for harps or zithers, which have very low values of $z$. On the contrary, they are notably different according to "acoustical converting efficiency." Woods traditionally used in lute- or guitar-like instruments in Latin America and in Asia might be described as, respectively, a little and a lot "less performant" than spruce on the basis of ACE. On the contrary, woods from these areas chosen for harp/zithers appear as much or more "performant" than spruce. Nevertheless, the very important point is that wood choice results from a long-term material-structure-music co-evolution, so that these woods are integrated to the "identity" of their respective instruments. Probably the same instruments built up with a "resonance" spruce top plate would be judged quite poorly by traditional musicians. Thus, this comparative analysis suggests that (i) although chosen woods appear to perform very differently according to "material performance indexes" (derived assuming comparable geometry), caution should be taken considering the variations in the structure of instruments. (ii) Differences in acoustical functioning, in playing modes and in cultural preferences on "sonority" further interact with the material-structure co-adaptation. As a result, the "western classical music instruments" choice of wood, considered as a "standard," cannot be extrapolated to other cultures for stringed instruments soundboards. 


\section{CONCLUSIONS}

A wide databank has been collected on the diversity of axial vibrational properties between 452 woody species, through experimental tests on a wide sampling from 79 species, extended by a thorough compilation of literature data. Distributions between broad categories show that softwoods, traditionally preferred for soundboards of Western string instruments, are indeed represented by lower densities and higher specific dynamic modulus, but that their internal friction ranges around the average value for all woods. On the other hand, tropical hardwoods are the only category in which the highest densities and Young's modulus, and the lowest internal friction, can be found. Thus they could hardly be replaced by temperate substitutes for some instrument parts. A relational database dedicated to "wood and instruments diversity" has been created for relating wood vibrational properties and uses in musical instruments of the world. This allowed comparing different wood species used in acoustically important parts of musical instruments from different geo-cultural areas. In the case of xylophone bars or slitdrums, woods used in different continents were widely scattered according to density and had overlapping, and average ranges in $E \% \rho$. But they were all characterized by very low internal friction and often belonged to close botanical groups. This suggests that several civilizations selected, from very diverse local flora, species appropriate to these instruments in which the damping properties of wood play a prominent role. On the contrary, in the case of woods used for strings soundboards, the only characteristic shared by species traditionally used in Asian, Latin American, and Western classical instruments is a moderate density. Hardwoods are often used even when local resources in softwoods are available. Vibrational properties of soundboard woods covered most of the global range for wood, some of them being more and some less "performant" (from a material indexes point of view) than "resonance" spruce for Western instruments. However, all the considered wood materials are perfectly adapted to the expected behavior of their respective instruments. Thus the present findings suggest that, besides differences in structure and acoustical functioning, cultural differences in playing mode and in subjective "sound" preferences probably participate in such different material choices. In the case of string instruments, the "Western" standard in wood choice could not be extrapolated to other geo-cultural areas.

However, although the collected set of data is probably the widest up to now, much effort is still needed, both on the vibrational characterization of various woody species, and on collecting reliable botanical information on species used in many instruments of the world. More data would also be needed concerning anisotropy, and within-species variability in properties. Additionally, much work is still needed to better understand wood qualification by makers. This is already the case for Western instruments, but nearly no information is available for other cultures of instrument making.

\section{ACKNOWLEDGMENTS}

The author thanks Y. ElKaïm (LMGC, Montpellier) and P. Cabrolier for helping in vibrational tests; P. Détienne,
C. Daigremont, and S. Lotte (CIRAD, Montpellier) and all instrument makers for providing or identifying wood material; J. Gril, B. Thibaut and C. Cooksey for critical reading and correcting the manuscript; K. Motegi, H. Komoda, K. Minato, S. Yoshikawa, K. Pourtahmasi, B. Traoré, and A. Quintanar Isaias for past fruitful discussions on extra-European instruments. This work has been supported by CNRS and CIRAD in France, and by JSPS in Japan.

${ }^{1}$ Information obtained by Dr. D. Cardon (CNRS, UMR5648, Lyon, France) during an ethnobotanical enquiry among craftsmen from Ambrym island, May 2008.

${ }^{2}$ No African string instruments are represented here, partly because many have a stretched skin "soundboard," but also because properties of the few documented woods are still unknown.

Aizawa, H. (1998). "Frequency dependence of vibration properties of wood in the longitudinal direction" (in Japanese), Master thesis, Faculty of Engineering, Kyoto University.

Aizawa, H., Obataya, E., Ono, T., and Norimoto, M. (1998). "Acoustic converting efficiency and anisotropic nature of wood," Wood Res. 85, 81-83.

Aramaki, M., Baillères, H., Brancheriau, L., Kronland-Martinet, R., and Ystad, S. (2007). "Sound quality assessment of wood for xylophone bars," J. Acoust. Soc. Am. 121, 2407-2421.

Barlow, C. (1997). "Material selection for musical instruments," Proc. Inst. Acoust. 19, 69-78.

Brancheriau, L., Baillères, H., Détienne, P., Gril, J., and Kronland, R. (2006). "Key signal and wood anatomy parameters related to the acoustic quality of wood for xylophone-type percussion instruments," J. Wood Sci. 52, 270-273.

Brémaud, I. (2006). "Diversité des bois utilisés ou utilisables en facture d'instruments de musique. (Diversity of woods used or usable in musical instruments making)," Ph.D. thesis, University of Montpellier II, p. 302.

Brémaud, I., Amusant, N., Minato, K., Gril, J., and Thibaut, B. (2011a). "Effect of extractives on vibrational properties of African Padauk (Pterocarpus soyauxii Taub)," Wood Sci. Technol. 45, 461-472.

Brémaud, I., Gril, J., and Thibaut, B. (2011b). "Anisotropy of wood vibrational properties: Dependence on grain angle and review of literature data," Wood Sci. Technol. 45, 735-754.

Brémaud, I., Minato, K., Langbour, P., and Thibaut, B. (2010). "Physicochemical indicators of the inter-specific variability in vibration damping of wood," Ann. For. Sci. 67, 707-715.

Brémaud, I., Minato, K., and Thibaut, B. (2009). "Mechanical damping of wood as related to species classification: a preliminary survey," in 6th Plant Biomechanics Conference PBM09, edited by B. Thibaut, 16-21 November, 2009, Cayenne, French Guyana, pp. 536-542.

Brémaud, I., Thibaut, B., and Minato, K. (2007). "A database linking woody species, vibrational properties, and uses in musical instruments of the world," in ISMA 2007, edited by J. Agullo and A. Barjau, 9-12 September, 2007, Barcelona, Spain, Paper No. 3-S2-4.

Bucur, V. (2006). Acoustics of Wood, 2nd ed. (Springer-Verlag, Berlin), p. 393.

Buksnowitz, C., Teischinger, A., Müller, U., Pahler, A., and Evans, R. (2007). "Resonance wood [Picea abies (L.) Karst.]—Evaluation and prediction of violin makers "quality-grading," J. Acoust. Soc. Am. 121, 2384-2395.

Carrington, J. F. (1976). "Wooden drums for inter village telephony in Central Africa,” J. Inst. Wood Sci. 7, 10-14.

Chaigne, A., and Doutaut, V. (1997). "Numerical simulations of xylophones. I. Time-domain modeling of the vibrating bars," J. Acoust. Soc. Am. 101, 539-557.

Dechamps, R. (1972). "Note préliminaire concernant l'identification anatomique des espèces de bois utilisées dans la fabrication des tambours à fente de l'Afrique Centrale" ("Preliminary note concerning the anatomical identification of wood species used in the making of slit-drums from Central Africa"), Africa Tervuren XVIII, 15-18.

Dechamps, R. (1973). "Note préliminaire concernant l'identification anatomique des espèces de bois utilisées dans la fabrication des xylophones de l'Afrique Centrale" ("Preliminary note concerning the anatomical identification of wood species used in the making of xylophones from Central Africa”), Africa-Tervuren XIX, pp. 61-66. 
Détienne, P., and Chanson, B. (1996). "L'éventail de la densité du bois des feuillus. Comparaison entre différentes régions du Monde" ("The span in wood specific gravity of hardwoods. Comparison between different regions of the World"), Bois For. Trop. 250, 19-30.

Douau, D. (1986). "Evaluation des propriétés acoustiques, mécaniques et structurelles des bois de tables d'harmonie de guitare; leur influence sur le timbre de l'intrument" ("Evaluation of the acoustical, mechanical and structural properties of woods for guitar soundboards; their influence on the timbre of the instrument"), Ph.D. thesis, Université du Maine, France, p. 137.

Earle, C. J. (2010). “The Gymnosperm Database,” http://www.conifers.org/ (Last accessed on November 2010).

Fletcher, N. H., and Rossing, T. D. (1998). The Physics of Musical Instruments (Springer Verlag, New-York), p. 756.

Fukada, E. (1950). "The vibrational properties of wood I.," J. Phys. Soc. Jpn. 5, 321-327.

Haines, D. W. (2000). "The essential mechanical properties of wood prepared for musical instruments," Catgut Acoust. Soc. J. 4, 20-32.

Hase, N. (1987). "A comparison between acoustic physical factors of Honduras rosewood for marimbas and xylophones and a sensory evaluation of these instruments (in Japanese)," Mokuzai Gakkaishi 33, 762-768.

Holz, D. (1996a). "Acoustically important properties of xylophone-bar materials: can tropical woods be replaced by European species?" Acust. Acta Acust. 82, 878-884.

Holz, D. (1996b). "Comments on" Chemical treatment of wood for musical instruments“"J. Acoust. Soc. Am. 96, 3380-3391]," J. Acoust. Soc. Am. 99, 1795-1796 (1994).

Hori, R., Müller, M., Watanabe, U., Lichtenegger, H. C., Fratzl, P., and Sugiyama, J. (2002). "The importance of seasonal differences in the cellulose microfibril angle in softwoods in determining acoustic properties," J. Mater. Sci. 37, 4279-4284.

Kaptain, L. (1991). "Maderas que cantan" ("Woods that sing"), Gobierno del estado de Chiapas, Instituto chiapaneco de cultura, Tuxtla Gutierrez, Chiapas, Mexico, p. 226.

Kubojima, Y., Okano, T., and Ohta, M. (1997). "Effect of annual ring widths on structural and vibrational properties of wood," Mokuzai Gakkaishi 43, 634-641.

Matsunaga, M., Minato, K., and Nakatsubo, F. (1999). "Vibrational property changes of spruce wood by impregnation with water-soluble extractives of pernambuco (Guilandina echinata Spreng.)," J. Wood Sci. 45, 470-474.

Minato, K., Ito, Y., and Sugawara, H. (2005). "Rationality of Kiri Wood (Paulownia tomentosa) in Traditional Uses" (in Japanese), J. Soc. Mater. Sci. Jpn. 54, 361-364.

Norimoto, M., Ono, T., and Watanabe, Y. (1984). "Selection of wood used for piano soundboards" (in Japanese), J. Soc. Rheol. Jpn. 12, 115-119.

Obataya, E., Norimoto, M., and Gril, J. (1998). "The effects of adsorbed water on dynamic mechanical properties of wood," Polymer 39, 3059-3064.
Obataya, E., Ono, T., and Norimoto, M. (2000). "Vibrational properties of wood along the grain,” J. Mater. Sci. 35, 2993-3001.

Ono, T., and Kataoka, A. (1979). "The frequency dependence of the dynamic Young's modulus and internal friction of wood used for the soundboard of musical Instruments II" (in Japanese), Mokuzai Gakkaishi 25, 535-542.

Ono, T., and Norimoto, M. (1983). "Study on Young's modulus and internal friction of wood in relation to the evaluation of wood for musical instruments," Jpn. J. Appl. Phys. 22, 611-614.

Ono, T., and Norimoto, M. (1984). "On physical criteria for the selection of wood for soundboards of musical instruments," Rheol. Acta 23, 652-656.

Pourtahmasi, K., and Se Golpayegani, A. (2008). "Introducing Mulberry's wood (Morus alba L.) used in bowl shaped musical instruments of Iran," in Le bois: instrument du patrimoine musical (Wood: Instrument of Musical Heritage), edited by S. Leconte and S. Vaiedelich, 29 May 2009, Cité de la Musique, Paris, pp. 78-87.

Richter, H. G. (1988). Holz als Rohstoff für den Musik-Instrumentenbau (Wood as Raw Material for Musical Instruments Making) (Moeck Verlag, Celle, Germany), p. 44.

Rujinirun, C., Phinyocheep, P., Prachyabrued, W., and Laemsak, N. (2005). "Chemical Treatment of Wood for Musical Instruments. Part I: Acoustically Important Properties of Wood for the Ranad (Thai Traditional Xylophone),"Wood Sci. Tech. 39, 77-85.

Salazar Salvatierra, R. (1994). "Instrumentos Musicales del Folclor Costarricense" ("Musical Instruments of the Costa Rican Folklore"), Editorial Tecnologica de Costa Rica, Cartago, Costa Rica, p. 228.

Schelleng, J. C. (1963). "The Violin as a Circuit," J. Acoust. Soc. Am. 35, 326-338.

Traoré, B., Brancheriau, L., Perré, P., Stevanovic, T., and Diouf, P. (2010). "Acoustic quality of vène wood (Pterocarpus erinaceus Poir.) for xylophone instrument manufacture in Mali," Ann. For. Sci. 67, 815-822.

Wegst, U. G. K. (2006). “Wood for sound,” Am. J. Bot. 93, 1439-1448.

Yano, H. (1994). "The changes in the acoustic properties of Western Red Cedar due to methanol extraction," Holzforschung 48, 491-495.

Yano, H., Kajita, H., and Minato, K. (1994). "Chemical treatment of wood for musical instruments," J. Acoust. Soc. Am. 96, 3380-3391.

Yano, H., Kyou, K., Furuta, Y., and Kajita, H. (1995). “Acoustic properties of Brazilian rosewood used for guitar back plate (in Japanese)," Mokuzai Gakkaishi 41, 17-24.

Yano, H., Matsuoka, I., and Mukudai, J. (1992). "Acoustic properties of wood for violins," Mokuzai Gakkaishi 38, 122-127 (in Japanese).

Yano, H., Oonishi, K., and Mukudai, J. (1990). "Acoustic Properties of Wood for the Top Plate of Guitar,” J. Soc. Mater. Sci. Jpn. 39, 1207-1212 (in Japanese).

Yoshikawa, S. (2007). "Acoustical classification of woods for string instruments," J. Acoust. Soc. Am. 122, 573-573. 